\title{
Subversal-Reversal of Institutions in the United States: Presidential Leadership Matters
}

\author{
Oluwole Owoye \\ Department of Social Sciences/Economics, Western Connecticut State University, Danbury, CT 06810, United States \\ E-mail: Owoyeo@wcsu.edu
}

Received: 24 September 2020; Revised: 2 November 2020; Accepted: 11 November 2020

\begin{abstract}
This paper uses theoretical analysis to provide a new perspective that the President of the United States (POTUS) in coordinated obsequiousness and complicity with the leaders of the Republican Party and other co-equal branches of government can subvert the rule of law and reverse the economic, political, and social (EPS) institutions. Studies have not examined the POTUS and the EPS institutions nexus because of the questionable and controversial perspective that the EPS institutions are strong enough to rein in any POTUS with autocratic aspirations. The assertion is that presidential leadership matters because the 45th POTUS's autocratic aspirations are instrumental in subverting the rule of law and reversing the EPS institutions. This paper further asserts that the adherence to democratic norms by all POTUS prior to 2017 mattered in building and strengthening the EPS institutions. In support of these assertions, this study uses theoretical institutional functions for periods before and after 2017 to provide a new perspective based on real evidence from the intentions-revealing, self-projections and self-deceptions statements of the 45th POTUS. This study derives the built and strengthened EPS institutions coefficients for pre-2017 periods in comparison to the post-2017 subvert and reverse EPS institutions coefficients to demonstrate that presidential leadership matters. The contention is that the future of the rule of law and the EPS institutions in the United States depends on the extent to which Congress is willing and able to exert its oversight powers in curtailing the 45th POTUS's autocratic aspirations and the abuses of executive powers; and that when these institutions cannot curtail the autocratic aspirations of the 45th POTUS, only the uncompromising and courageous voters can.
\end{abstract}

Keywords: subversal and reversal, presidential leadership, EPS institutions, 45th POTUS

JEL Classification: D72, H11, H77, K00, O17, O43, P26

\section{Introduction}

This study asserts that the 45th President of the United States (POTUS) in strategically coordinated complicity with leaderships of the other co-equal branches of government can invoke the concept of law and order to subvert the rule of law and reverse the economic, political, and social (EPS) institutions. This assertion also holds true for any of the highly industrialized countries worldwide. Until now, studies have not examined the relationship between presidential leadership of the United States and the EPS institutions because research scholars hold on to the questionable and

Copyright (C2020 Oluwole Owoye

DOI: https://doi.org/10.37256/ges.212021657

This is an open-access article distributed under a CC BY license

(Creative Commons Attribution 4.0 International License)

https://creativecommons.org/licenses/by/4.0/ 
controversial perspective that highly advanced countries have strong EPS institutions required to rein in the autocratic aspirations of presidential leaderships. For over two centuries, American presidents traditionally embraced the rule of law with which they built strong EPS institutions, and as a result, research scholars assumed that every POTUS had democratic ideals. In this watershed moment in which the rule of law and the EPS institutions are under severe attacks in the United States, it is important to provide a new perspective on the relationship between presidential leadership, the rule of law, and the EPS institutions. This study contributes to the theoretical literature and debate by examining presidential leadership, the rule of law, and the EPS institutions nexus because of the 45th POTUS's revealed autocratic aspirations and the desires to undermine the rule of law and the EPS institutions regardless of a majority or a divided Congress.

This study provides the theoretical analysis with which to examine whether the 45th POTUS can subvert the rule of law and reverse the EPS institutions as authoritarian leaders do worldwide. In analyzing this issue, this paper asserts that the EPS institutions in United States depends significantly on the democratic ideals or autocratic aspirations of presidential leaderships. This paper further contends that many of the previous presidential leaders prior to 2017 exhibited the traditional democratic ideals, which they used to build and strengthen the EPS institutions, even though some of them deviated from the norms. According Levitsky and Ziblatt (2016a, 2016b), over the last century, no majorpresidential candidate, except Richard Nixon, rejected the democratic rules of the game, denied the legitimacy of their opponents, appeared to tolerate or encourage violence, and expressed a willingness to curtail the civil liberties of their opponents. To support the assertion of this paper, this study derives the built and strengthened EPS institutions coefficients to demonstrate the effects of presidential leaderships on these institutions prior to 2017.

The 45th POTUS continued to display unprecedented revealed preference for autocracy as shown by his open disdain for democratic norms, the rule of law, the EPS institutions, and the separation of powers between the three coequal branches of government since his inaugural address in 2017. The constant denigration and abuse of the Federal Bureau of Investigation (FBI), Central Intelligence Agency (CIA), the National Security Agency (NSA), Military Generals (MGs), the mainstream media, and individual Congressional representatives show the disdain for these institutions. Essentially, the 45th POTUS prefers to subvert the rule of law and reverse the EPS institutions in his push to achieve autocracy. To support this assertion, this study derives subvert and reverse EPS institutions coefficients based on the evidence from the 45th POTUS's intentions revealing, self-projections and self-deceptions speeches and tweets. These coefficients highlight the damages to the rule of law and the EPS institutions since January 2017 and into the near future if Republican Party retains the White House and Congress remains divided.

The concept of intentions-revealing statements draws from Samuelson's $(1938,1948)$ theory of revealed preference, which states that a consumer chooses the most preferred bundle of goods and services from those available. Applying the theory of revealed preference (Samuelson's $(1938,1948)$ theory of revealed preference assumes that the preference of consumers can be revealed based on their purchases, given their income constraints. In the context of presidential leaderships, the preference or intention of any POTUS with respect to political ideology and the EPS institutions can be revealed through legislative proposals or agenda and statements while in office) to presidential leadership and EPS institutions nexus, the contention is that the 45th POTUS has openly revealed his preference for autocracy and the desire to subvert and reverse the EPS institutions instead of building and strengthening the strong EPS institutions that brought him to the presidency of the United States. From the speeches, tweets, and interviews of the 45th POTUS, one can easily deduce that these actions revealed his preference for EPS institutions that will obey his commands in order to achieve his autocratic aspirations. More importantly, scholars who are skeptical as to whether the 45th POTUS's speeches, tweets, and interviews can be used as evidence of intentions-revealing need to be reminded of what the late poet Maya Angelou said: "When someone shows you who they are, believe them the first time" because a person's words reveal intentions and actions to be taken. Experts such as Levitsky and Ziblatt (2018) who studied demagogic political leaders around the world believe that we should take the words of demagogic political leaders seriously because their words signal the actions they plan to take. In addition, self-deception and self-projection theories (For detailed discussions on the theories of self-deceptions and self-projections, see Mele (1998), and Gur and Sackeim (1979)) deal with human behavior, and leadership behavior is a topic that could be examined from different disciplines. The concept of self-deception involves intentionally misleading oneself into believing otherwise, and self-projection is the conscious effort of projecting oneself unto others as a way to feel vindicated thus creating false believe.

These interdisciplinary theories are pivotal in understanding the strategies employed by the 45 th POTUS to subvert 
the rule of law and reverse the EPS institutions. From the intentions congruence of the 45th POTUS and Congressional Republicans to subvert and reverse the EPS institutions, one can surmise that this is purely partisan political complicity so that the Republican Party can achieve absolute power over all the branches of government. Based on the policy actions of the Republican Party in the past five or more decades, one can also deduce that they prefer the 45th POTUS, which according to Levitsky and Ziblatt (2018) is their long awaited self-deceiving and self-projecting "extremist outsider." Simply put, the 45th POTUS is their extremist outsider, which Republicans needed to achieve absolute power in order to transform American democracy into autocracy by gradually subverting the rule of law and reversing the EPS institutions.

In hindsight, one can presume that the Republican Party's desire for absolute power over all the branches of government and the EPS institutions may explain their relentless efforts in gerrymandering congressional districts and passing laws to disenfranchise African Americans and other minority voters in order to control their rights. Arguably, the policy actions of the Republican Party and the 45th POTUS reveal that they prefer gerrymandered districts, voter suppressions, complete control of the three co-equal branches of government, and foreign interferences in elections. While these are the necessary and sufficient conditions in subverting and reversing the rule of law, the EPS institutions, and all the political norms, they are in fact the preconditions for take-off and the death or unraveling of democracy as it transitions to autocracy.

At this moment, the United States provides a powerful case study with respect to its EPS institutions, which research scholars can examine with new perspective. It is important to reexamine the relationship between presidential leadership and the EPS institutions in order to analyze some relevant research questions because democracies around the world are confused to see the rapidly unraveling of American democracy (Greenberg, 2020; Acemoglu, 2020). Is American democracy unraveling because its rule of law and EPS institutions are undermined? Can the 45th POTUS subvert the rule of law and reverse the institutional pillars of American democracy? If so, how and what does it mean? If due to intentions congruence of the 45th POTUS and the Republican Party the United States transitions into autocraticdemocracy, could this signal the beginning of an era of global autocracy contagion or a new world order couched under law and order that autocrats prefer? These are some of the research questions that proxies and/or instrumental variables cannot answer, but possible within the preponderance of intentions revealing and self-projections-deceptions statements provided by the 45th POTUS.

Based on the theoretical framework utilized to analyze the 45th POTUS's speeches, tweets, and interviews, this paper concludes that he has revealed his autocratic propensities and intentions to subvert the rule of law and reverse the EPS institutions. More importantly, this study contends that the future of the rule of law and the EPS institutions in the United States will depend on whether the subvert and reverse EPS institutions coefficients are much stronger than the built and strengthened EPS institutions coefficients derived from the theoretical analysis. Given the apparent obsequiousness of the Republican Party in this toxic political environment of partisan polarization, systemic racism, and diminished legislative oversights in either a majority or a divided Congress, the rule of law and the EPS institutions may not be strong enough to rein in the 45th POTUS's autocratic aspirations. Simply put, if Congress and the EPS cannot curtail the 45th POTUS's autocratic impulses, then the demand for accountability rests on the rational and courageous voters.

This paper is organized as follows. Section 2 provides the background studies in order to shed some light on the ongoing debate among institutional economists and growth theorists about the primacy of institutions in economic growth and development. Section 3 presents the theoretical analysis of the relationship between presidential leadership and the EPS institutions in order to provide a new perspective to the literature that institutions in the United States are not sacrosanct, and that an enabled POTUS with autocratic aspirations can subvert the rule of law and reverse the EPS institutions. Section 4 provides the intentions-revealing and self-projecting-deceiving statements of the 45th POTUS to reveal his intentions to subvert and reverse these institutions, and more importantly, to analyze that presidential leadership matters with respect to these institutions. On one the hand, while the previous POTUS's democratic aspirations were instrumental in building and strengthening the institutional bedrock of American democracy, on the other hand, the 45th POTUS's autocratic aspirations couched under law and order would subvert and reverse these institutions. Section 5 provides concluding remarks with political implications. 


\section{Background literature}

According to economic historians, Thorstein Veblen was the founding father of the institutional economics school of thought, which did not gain much attention until the 1960s. Since the landmark seminal work of Buchanan and Tullock (1962), which North $(1971,1973,1990)$ built upon, the importance of institutions, as one of the major predicaments in the determination of economic growth in poor developing countries, has been part of the on-going debate. The studies by North and Thomas (1973) laid the theoretical foundation for the power of institutions as a key determinant of economic growth and development in many advanced economies. According to North and Thomas' works, the growth of the advanced economies of Europe occurred through the process of institutional development, which led to the establishment of property rights and the expansion of markets that eventually culminated in the Industrial Revolution. Growth theorists did not embrace this new institutional theory because it lacked empirical evidence; however, it gained prominence when Barro (1991, 1997, 1999), Knack and Keefer (1995), and Hall and Jones (1999) found evidence in support of North's hypothesis.

The current emphasis on the institutions hypothesis stems from Acemoglu et al. (2001) who employed different instruments, including the variability in mortality rates of European colonial settlers, as proxy for institutions in their growth regressions. According to these authors, the mortality rates shaped the strategies the colonial settlers adopted in setting up institutions in those colonies. They argued that in disease prone colonies, the settlers established extractive or exploitive institutions while in more favorable colonies, the settlers created institutions that supported property rights and restricted expropriations. They found that the differences in income per capita in former European colonies could be attributed to the differences in the institutions, and that after accounting for institutional differences, the geographic variables had no influence on income per capita (There are many empirical studies over the past two decades that provided evidence in support of the institutions hypothesis (Przeworski et al., 2000; Rodrik et al., 2002; Kaufman \& Kraay, 2002; Easterly \& Levine, 2003; Acemoglu et al., 2005; Rodrik \& Wacziarg, 2005; Persson \& Tabellini, 2006)).

Studies by Rodrik et al. (2002), Kaufman and Kraay (2002), and Easterly and Levine (2003) provided further evidence in support of the institutions hypothesis (Przeworski et al., 2000; Acemoglu et al., 2005; Rodrik \& Wacziarg, 2005; Persson \& Tabellini, 2006). In related studies, Acemoglu (2003, 2009), and Rodrik and Subramanian (2002) claimed the primacy of institutions in explaining economic growth over the geography or natural resources/endowments and policy governance hypotheses. Sachs (2003) repeatedly cautioned that "institutions matter, but not for everything," "institutions don't rule," and that a "single-factor explanation of something as important as economic development can be alluring" because the primacy of a single causal factor could lead to erroneous inferences.

Glaeser et al. (2004) questioned the validity of the instrumental variable specifications used by proponents of the institutions hypothesis because the measures of institutions with which these proponents arrived at their conclusions came from several sources such as the International Country Risk Guide (ICRG) and the Polity IV. Furthermore, Glaeser et al. (2004) argued that these measures neither reflect the constraints on governments nor measure the permanent or at least durable features of the environment and they pointed out some shortcomings in these studies. First, they pointed out that "at the purely econometric level, this evidence suggests that predictors of settlement patterns are not valid instruments for institutions." Second, they noted that the three data sets measure outcomes, not permanent country-specific characteristics, which Douglas North referenced because the data sets from the ICRG (The ICRG is an aggregated index of survey assessments of government effectiveness in which statistical tables assign values to the 22 indicators underlying ICRG's business-oriented model for quantifying risk, examining such country-specific elements as currency risk, political leadership, the military and religion in politics, and corruption) and Polity IV measure different things such as government effectiveness or the limits of executive power and not institutions. Third, they pointed out that Knack and Keefer (1995), Hall and Jones (1999), and Acemoglu et al. (2001) obtained their measures of institutions from ICRG while Rodrik et al. (2002) used the aggregated index of mostly survey assessments of government effectiveness, developed and computed by Kaufman et al. (2002).

Studies by Besley and Kudamatsu (2007) and Olson (2003) examined the role of leadership and policy choices under different power structures, while Jones and Olken (2005) examined the impact of a leader's sudden death on economic growth. Chabal and Daloz (1999) and Bueno de Mesquita et al. (2003) examined the impact of leadership power structures on growth based on the selectorate and the winning coalitions that leaders put together. According to Bueno de Mesquita et al. (2003), leaders in democratic and dictatorial settings operate under different institutional 
constraints. According to these authors, institutional constraints limit the discretionary powers of leaders in democratic regimes thus compelling them to channel their political survival behavior towards growth-enhancing policies. In addition, they argued that leaders exhibit the propensity to choose growth-retarding policies (The "land redistribution policy" in Venezuela under Chavez and in Zimbabwe under Mugabe provides a good illustration of leaders in autocracies choosing growth-retarding policies where there are weak institutional constraints) in dictatorial regimes where there are few institutional constraints on presidential leaderships, and they show the desire to maintain power and compensate their few inner cronies. According to Knutsen (2010), the propensity for dictatorial regimes to select growth-retarding policies is more pronounced in Africa due to weak or no institutional constraints (These studies address an issue that Easterly and Levine (2003) raised with respect to the choices of growth-enhancing policies in some countries but growth-retarding policies in others such as African countries).

In Levitsky and Ziblatt's (2018) recent book about how democracies die, they laid out the important roles that the elected autocratic leaders play in the death of democracies in developed and less developed countries. They argued that democracies do not die at the "hands of generals," but at the hands of elected leaders who subvert the basic process with which they gained political power. They also argued that if "the political parties, organized citizens, democratic norms do not defend the constitutions, or unwritten rules of toleration and restraint, institutions alone are not enough to rein in elected autocrats." In support of this assertion, Levitsky and Ziblatt (2018) cited countries such as Hungary, Venezuela, Ecuador, Georgia, Peru, the Philippines, Poland, Russia, Turkey, Ukraine, Sri Lanka, and others where their elected would-be autocratic leaders undermined democratic institutions and constitutions. In addition, they argued that other nominally democratic institutions remain in place where people continue to vote in rigged and shammed elections. Studies by Dorf (2016), Smith (2018), Alberta (2019), Greenberg (2020), and Acemoglu (2020) conclude that American democracy is unraveling under the Trump's administration.

\section{Presidential leaderships and the EPS institutions}

As Bueno de Mesquita et al. (2003) pointed out, presidential leaderships in democratic and authoritarian settings operate under different institutional constraints. In a representative democracy, such as the United States, the strong EPS institutional constraints limit the discretionary powers of presidential leaderships, thus compelling them to channel their political survival behavior in the direction of growth-enhancing policies. In authoritarian regimes where there are few or no institutional constraints on leaders and there is the desire to be president-for-life and compensate the few inner cronies, there is the propensity to choose reckless transactional domestic and foreign policies that are growth retarding. This study concurs with the basic premise of Bueno de Mesquita et al. (2003) that leaders in democratic and authoritarian settings operate under different institutional constraints. The institutional constraints that limit the discretionary powers of leaders in democratic regimes are possible only when the legislative and the judiciary branches of government use their oversight powers to check the executive overreach or abuse of powers or the authoritarian aspirations of the executive branch of government.

This paper posits that the two-party system in the United States with its strong EPS institutional constraints on any POTUS could transform into autocratic-democracy if the Democrats or the Republicans in either a majority or a divided Congress are obsequiously complicit in any POTUS's executive power overreach, abuses of executive power, and autocratic aspirations. In the current hyperpartisan polarized political environment, the Republican Party still controls the Senate in a divided Congress, the Executive Office, and de-facto Judiciary branches of government. It is apparent to every rational American that the Congressional Republicans prefer to overlook rather than use their oversight powers to check the 45th POTUS's strategic maneuvers to subvert the rule of law and reverse the EPS institutional constraints.

Figure 1 provides the schematic illustration of the relationship between leaderships, constitutional rule of law, and the interdependent EPS institutions during different administrations. This diagram gives the visual depiction of North's (1971) argument regarding the rule of law as the guardrail in establishing property rights, and Sachs' (2003a) assertion that "Institutions Don't Rule." This assertion is also consistent with and corroborated by Levitsky and Ziblatt's (2018) recent assertion that "Institutions alone are not enough to rein in elected autocrats" and that the Constitution of the United States is "only a piece of paper," which "is not self-enforcing." In well-functioning democracies, such as the United States, the rule of law provides the necessary constitutional guardrails for the three co-equal branches of 
government and the EPS institutions, and the effectiveness of these institutions depends on leaderships' adherence to the rule of law and all democratic norms. More importantly, the rule of law, as interpreted by the Supreme Court of the United States, holds everyone including the current and former presidents, legislative and judiciary leaders, generals, sheriffs or police officers, citizens, and illegal immigrants equal under the law. Most fundamentally, the rule of law requires that people in positions of leaderships at the executive, legislative, and judiciary branches of government and at any of the EPS institutions should exercise their power within a constraining framework of public norms, rather than on the basis of their own preferences (Dorf, 2016).

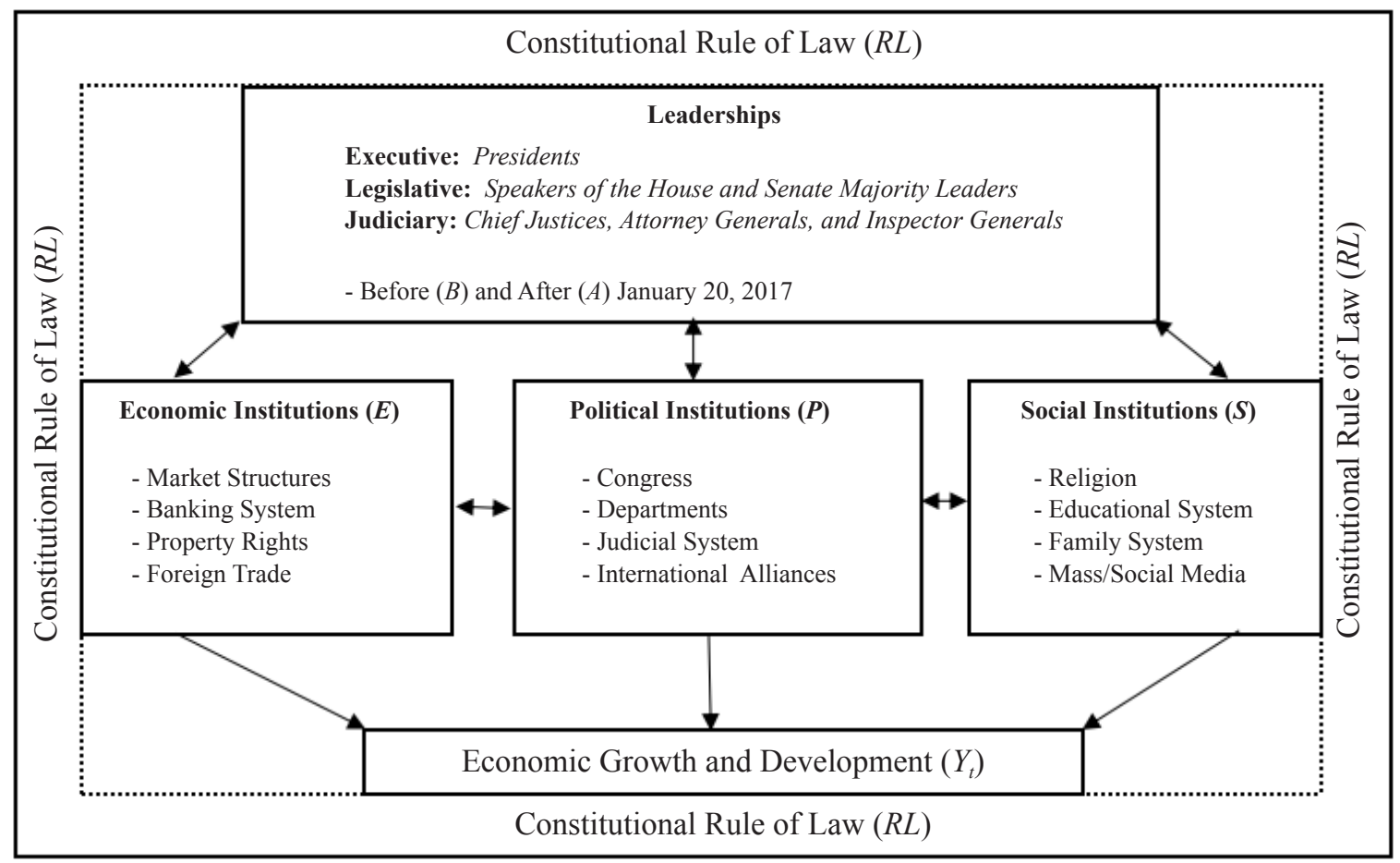

Source: Drawn by the author to simplify leaderships and EPS institutions nexus

Figure 1. Presidential leaderships and EPS institutions in the United States

In a covertly coordinated environment of complicity among leaders at the three co-equal branches of government, sanctioned by the POTUS, they can dictate the directions of the rule of law, the EPS institutions, and economic growth; therefore, the main purpose of Figure 1 is to amplify Sachs' (2003a) argument that institutions do not rule. According to Levitsky and Ziblatt (2018), the Constitution or the rule of law is not self-enforcing. Simply put, presidential leaderships in collusion with leaders of other co-equal branches matter because they govern these institutions, and they can invoke law and order politics to manipulate both the Constitution and the rule of law for their self-interests. Given the governance structure in the United State, the POTUS endowed with democratic ideals would be guided by the rule of law in building and strengthening the EPS institutions rather than invoke law and order to undermine the rule of law in which the goal is to subvert and reverse the EPS institutional pillars of American democracy. In some countries where ambitious would-be autocrats ascend to power, their objective is to cause political chaos and confusion. According to Smith (2018), would-be autocrats tend to invoke law and order because they are driven by social dominance orientation or authoritarianism. In the process, they use law and order politics to undermine the rule of law, and ultimately, they subvert and reverse the EPS institutional constraints because their aim is to achieve autocratic power or the presidentfor-life.

In addition, the bidirectional downward arrows in Figure 1 provide a real world look at the dynamic complex relationships to show that leaderships at the three co-equal branches matter with respect to the rule of law and the 
EPS institutions in countries worldwide. The bidirectional horizontal arrows show the interdependence of the EPS institutions necessary to sustain economic growth. Expressing these complex relationships in composite functional form yields:

$$
Y_{t}=f[I(R L, P L(C B)), \boldsymbol{Z}]
$$

where $Y_{t}$ is the measure of economic growth, $I$ represents the economic $(E)$, political $(P)$, and social $(S)$ institutions; $R L$ represents the rule of law-a measure of societal normality; $P L$ represents presidential leaderships and their innate democratic ideals traditionally associated with every administration; and $C B$ captures the required checks and balances on presidential leaderships provided by the legislative and judiciary branches of government. In addition, $\boldsymbol{Z}$ is a vector of other determinants of economic growth such as physical and human capital, fertility rates, government consumption ratio, rule of law index, terms of trade, democracy index, and inflation rate. In a cross-country study, Barro (1997) provided the empirical evidence to show the statistical significance of these variables in determining economic growth.

The focus of this study is that presidential leaderships matter in building and strengthening or in subverting and reversing the rule of law and the EPS institutions in the United States in two different periods. This is important because the 45th POTUS demonstrates that a bullish leader at the executive branch can intimidate leaders at the other co-equal branches of government until they acquiesce to his autocratic aspirations. The $I(R L, P L(C B))$ component of equation (1) captures this important assertion. For clarity and comprehension, let $I_{B}$ and $I_{A}$ denote the EPS institutions, $R L_{B}$ and $R L_{A}$ stand for the rule of law, $P L_{B}$ and $P L_{A}$ represent presidential leaderships, $C B_{B}$ and $C B_{A}$ symbolize the checks and balances provided by the legislative and judiciary branches of government, and subscripts $B$ and $A$ imply before and after January 20, 2017, respectively.

According to institutional research scholars such as Acemoglu, Rodrick, Subramanian, and others, strong EPS institutions in democracies serve to check the authoritarian aspirations of presidential leaderships in contrast to weak institutions normally associated with autocracies worldwide. The consensus among growth theorists is that transformational presidential leaderships in democracies have positive impact on economic growth because these transformational presidential leaders have the traits required to put their countries on sustainable economic growth paths. In contrast, transactional presidential leaders lack the necessary traits thus the negative impact on economic growth and development. According to Acemoglu et. al (2002a, 2002b), Acemoglu (2003, 2009), economic growth is positive in advanced democratic countries because they are assumed to have strong institutions, but negative in less developed countries governed by brutal autocrats where there are weak or no EPS institutional constraints.

Given that the focus of this study is on the relationship between presidential leaderships and the EPS institutions, the issue for theoretical analysis is whether the 45th POTUS prefers to govern with undermined EPS institutions rather than strong institutions with the robust checks and balances, and if there is any data evidence to show his revealed preference. The theoretical analysis is pertinent because presidents worldwide have enormous power to build and strengthen EPS institutions if they adhere to democratic ideologies or undermine these institutions in order to control all the branches of government if they have autocratic aspirations. In the 20th century, some western democracies such as Germany, Italy, Spain, Portugal, and Greece transitioned into autocracies due to the "strongmen leadership syndrome." This lends credence to the assertion that institutions do not rule, but leaders do through the formulation and implementation of prudent policies that mitigate income and gender inequalities, climate change, environmental pollution, and many other issues. Based on the "intentions-revealing, self-deceptions, and self-projections" documentary evidence of the 45th POTUS, one can deduce that he prefers to govern under weak subservient institutions as evidenced by his exercise of unchecked executive power to subvert the rule of law and reverse and the strong EPS institutions in the United States.

The current political economy of the United States provides the ideal case study in which to examine presidential leaderships and the EPS institutions nexus for a host of reasons. First, Acemoglu (2020), who has been a major proponent of the primacy of institutions over the past two or more decades, is convinced that the Trump's presidency is rapidly unraveling the institutional pillars of democracy in the United States. Given Acemoglu's (2020) seismic shift in perception about institutions, this study therefore provides the theoretical explanations of the subversions of the institutions instrumental to unraveling democracy in the United States. Second, the United States is extremely divided due to different political ideologies, and this is manifested in the hyperpartisan Congress and the electorate. In 
other words, a divided United States provides a fertile ground for a would-be autocratic president to test the strength of the institutional pillars of American democracy. Third, the relentless efforts of the Republican Party to gerrymander congressional districts, voter suppressions, and the apparent complicity with foreign interferences in elections could be interpreted as their concealed preference for autocracy in the United States.

Fourth, due to the congruence of the 45th POTUS's autocratic intentions with the strategies of the Republican Party, one can surmise that they prefer the 45th POTUS because he has enabled and empowered them to reveal their long concealed political preference for a one-party democracy in the United States. In essence, the 45th POTUS provides the best illustrative example of a powerful "insurgent-outsider" with the expertise on information distortions, on how to sell hate-creating stories and false narratives that the Republican base voters willingly and easily consume, which would ultimately overwhelm everyone. More importantly, the 45th POTUS is adept in promoting racial-political divisions and in invoking law and order to subvert the rule of law and reverse strong EPS institutions in the United States. Fifth, the 45th POTUS is taking the United States through the final preconditions (undermining the rule of law and the EPS institutions) for take-off to achieve his transition to autocracy, which may usher in global autocracy contagion.

These reasons are consonant with Levitsky and Ziblatt's (2018) argument that when established parties opportunistically invite "extremists outsiders" into their ranks, they imperil democracy in that once a would-be autocrat makes it to power, democracy faces a survival test as autocratic presidential leaders will subvert and reverse democratic institutions that would constrain them. In addition, they pointed out that "Without robust norms, constitutional checks and balances do not serve as the bulwarks of democracy we imagine it to be. Instead, institutions become political weapons, wielded forcefully by those who control them against those who do not. This is how elected autocrats subvert and reverse democracy-packing and 'weaponizing' the courts and other neutral agencies, buying off the media and private sector (or bullying them into silence), and rewriting the rules of politics to permanently disadvantage their rivals."

The 45th POTUS's constant engagements in efforts to undermine democratic norms are manifested by his audacious contempt for American political institutions and the rule of law. The desire to undermine the EPS institutions to achieve autocratic power deserves conceptual analysis in order to comprehend the looming consequences. The relationship between presidential leaderships and the EPS institutions as espoused within the constitutional norms can be expressed in EPS institution-functional forms, similar to the standard Cobb-Douglas production function:

$$
I_{B}=R L_{B}\left(P L_{B}\right)^{\beta}\left(P L_{B} \cdot C B_{B}\right)^{\theta}\left(P L_{B} \cdot S M V_{B}\right)^{\mu}
$$

and

$$
I_{A}=R L_{A}\left(P L_{A}\right)^{-\delta}\left(P L_{A} \cdot C B_{A}\right)^{-\sigma}\left(P L_{A} \cdot V M V_{A}\right)^{-\psi}
$$

where $R L_{B}, R L_{A}, P L_{B}$, and $P L_{A}$ are as defined in equation (1), $P L_{B} \cdot C B_{B}$ and $P L_{A} \cdot C B_{A}$ represent the composite-interactive terms intended to capture the checks and balances $\left(C B_{B}\right.$ and $\left.C B_{A}\right)$ provided by the legislative and judicial oversights on presidential leaderships during different regimes. More importantly, $P L_{B} \cdot S M V_{B}$ and $P L_{A} \cdot V M C_{A}$ capture the extent of power of the silent majority voting $\left(S M V_{B}\right)$ and the vocal minority voting $\left(V M C_{A}\right)$ citizens because the fate of the rule of law and the EPS institutions will depend on the extent to which American voters could hold any POTUS, either with democratic principles or apparent authoritarian power, accountable.

For simplicity, let us assume that the rule of law is sacrosanct, which means it cannot be undermined in any law abiding administration (that is, $R L_{B}=R L_{A}$ ), then $I_{B}$ as specified in equation (2) is strictly increasing in $P L_{B}, P L_{B} . C B_{B}$, and $P L_{B} . S M V_{B}$. In any law and order (chaotic/lawless) administration, $I_{A}$ in equation (3) is strictly decreasing in $P L_{A}, P L_{A}$. $C B_{A}$, and $P L_{A} \cdot V M V_{A}$ which leads one to conclude that presidential leaderships, legislative with judicial oversights, and vocal or diehard minority voters can explain the difference between $I_{B}$ and $I_{A}$. Essentially, $P L_{B}$ and $P L_{A}, P L_{B} . C B_{B}$ and $P L_{A} \cdot C B_{A}$ as well as $P L_{B} \cdot S M V_{B}$ and $P L_{A} \cdot V M V_{A}$ vary depending on the extent to which Congress can exert its legislative oversights as enshrined in the Constitution of the United States; and the power of the silent majority voters vis-à-vis the vocal/diehard minority voters. Transforming equations (2) and (3) into logarithm-linear (The variables in equations (4) and (5) are expressed in lower cases because they are in logarithm forms) forms yields: 


$$
i_{B}=r l_{B}+\beta p l_{B}+\theta p l_{B} \cdot c b_{B}+\mu p l_{B} \cdot s m v_{B}
$$

and

$$
i_{A}=r l_{A}-\delta p l_{A}-\sigma p l_{A} \cdot c b_{A}-\psi p l_{A} \cdot v m v_{A}
$$

To provide a clear interpretation of equation (4), the partial differentiations of with respect to the explanatory variables on the right hand side yield:

$$
\begin{gathered}
\frac{\partial i_{B}}{\partial r l_{B}}=1 \\
\frac{\partial i_{B}}{\partial p l_{B}}=\beta \\
\frac{\partial i_{B}}{\partial c b_{B}}=\frac{\partial i_{B}}{\partial p l_{B}} \cdot \frac{\partial p l_{B}}{\partial c b_{B}}=\theta
\end{gathered}
$$

and

$$
\frac{\partial i_{B}}{\partial s m v_{B}}=\frac{\partial i_{B}}{\partial p l_{B}} \cdot \frac{\partial p l_{B}}{\partial s m v_{B}}=\mu
$$

Equation (6) confirms the constitutional rule of law, which solidified the guardrails that helped to build and strengthen the EPS institutions in all presidential administrations before 2017. Also, $\beta$ is the coefficient for leadership adherence to democratic principles, which measures the degree to which the previous presidential leaderships, at least, conformed to all institutional norms. According to presidential historians, even though some presidential leaders deviated from the norms, but overall, their adherence to democratic norms helped built and strengthened the vital institutional pillars of representative democracy in the United States. Similarly, $\theta$ is the coefficient for compliance to the checks and balances, that is, the extent to which the previous presidential leaderships complied and functioned under robust checks and balances provided by the legislative and judiciary branches of government, which further built and strengthened the EPS institutions. Finally, $\mu$ is the coefficient of support from the courageously silent majority voters who prefer presidents that exhibit democratic ideologies.

Next, equation (5) provides a clear interpretation by showing how the 45th POTUS engaged in concerted efforts to subvert the rule of law and reverse the EPS institutions as manifested by the unchecked violations of the emoluments clause and the anti-nepotism statute (The detailed discussions of anti-nepotism in government in the United States are provided in 5 U.S. Code $\S 3110$-Employment of relatives: restrictions at https://www.law.cornell.edu). Congressional Republicans are completely obsequious to these actions. The partial differentiations of $i_{A}$ with respect the explanatory variables yield:

$$
\begin{gathered}
\frac{\partial i_{A}}{\partial r l_{A}}<1 \text { or } \frac{\partial i_{A}}{\partial r l_{A}} \leq 0 \\
\frac{\partial i_{A}}{\partial p l_{A}}=-\delta \\
\frac{\partial i_{A}}{\partial c b_{A}}=\frac{\partial i_{A}}{\partial p l_{A}} \cdot \frac{\partial p l_{A}}{\partial c b_{A}}=-\sigma
\end{gathered}
$$




$$
\frac{\partial i_{A}}{\partial v m v_{A}}=\frac{\partial i_{A}}{\partial p l_{A}} \cdot \frac{\partial p l_{A}}{\partial v m v_{A}}=-\psi
$$

If compared to equation (6), equation (10) shows the indeterminate damage to the EPS institutions when the 45th POTUS uses law and order to subvert the rule of law. The $-\delta$ is the coefficient that measures the degree of contempt for institutional norms by 45th POTUS since his main objective is to subvert and reverse the EPS institutional pillars of democracy, which many institutional economists now admit (Acemoglu, 2020).Furthermore, while $-\sigma$ is the coefficient that measures the noncompliance to checks and balances, and fundamentally, this captures the magnitude of Congressional obsequiousness and complicity, and the abdications of oversight powers, which enabled and emboldened the 45th POTUS's noncompliance to checks and balances; $-\psi$ is the coefficient that captures the extent of the unwavering support of the vocal/diehard minority voters who prefer the 45th POTUS despite the display of autocratic impulses.

Given the coefficients of equations (6)-(9), one can surmise that not every POTUS was perfect before 2017, but they respected the robust checks and balances, which solidified the rule of law with which they built and strengthened the vital EPS institutions. Now that the United States is in the era of extreme political partisanship, the coefficients of equations (10)-(13) indicate the relentless efforts by the 45th POTUS, the complicit Congressional Republicans, and the vocal minority voters to turn representative democracy into autocracy, which they hope to achieve if they retained the White House and regain control of Congress in 2020 or 2024. Essentially, the strong EPS institutions associated with the strongest democracy in the world is unraveling due to the 45th POTUS's revealed autocratic aspirations, the complicity of Congressional Republican given their inability to exercise their oversight powers, and the unwavering support from the vocal minority voters. It is important to note that $\beta+\theta+\mu$ capture the initial components of the built and strengthened EPS institutions coefficients prior to 2017, while $-(\delta+\sigma+\psi)$ capture the ongoing subvert and reverse EPS institutions coefficients. These coefficients demonstrate actions that are not easily quantifiable for statistical estimation, but are highlighted and supported by the real documentary evidence of the 45th POTUS's behavior while in the White House.

\section{Documentary evidence of the 45th POTUS and EPS institutions nexus}

How can research scholars determine whether the 45th POTUS prefers to subvert the rule of law and reverse the EPS institutions? Can the 45th POTUS transform the strong EPS institutions, which are intended to control the presidential leaderships' autocratic impulses, to weak subservient institutions normally found in autocracies? In the absence of time-series data, what reliable evidence can researchers use to show the 45th POTUS prefers to subvert and reverse the EPS institutions? To answer these questions and those posed elsewhere in this paper as to how the 45th POTUS can subvert and reverse the institutional pillars of American democracy, this section provides the intentionsrevealing, self-projections, and self-deceptions statements through interviews or tweets of the 45th POTUS to highlight his intentions regarding the EPS institutional pillars of democracy in the United States.

In essence, equation (5) highlights the potential damage and/or the efforts to subvert and reverse the EPS institutions when Congressional Republicans exhibit complicit obsequiousness to the 45th POTUS. In other words, the partial subvert and reverse EPS institutions coefficients $(-\delta,-\sigma$, and $-\psi)$ derived in equations (11)-(13) show the magnitude to which the interdependent EPS institutions would be subverted and reversed if Republicans hold on to power in the White House with either a united or divided Congress, and the vocal minority voters remain unwavering. Either way, the 45th POTUS is empowered by the Republican Party, more than any POTUS before now, to subvert the rule of law and reverse the EPS institutions. To fully comprehend the threats that the 45th POTUS poses to the rule of law and the EPS institutional pillars of democracy, which are the final preconditions required for American democracy to die (Levitsky \& Ziblatt, 2018), it is important to analyze the efforts to undermine the rule of law as well as subvert and reverse these vital EPS institutions. These analyzes are central in order to derive the complete subvert and reverse EPS institutions coefficients. 


\subsection{Efforts to subvert and reverse economic institutions}

The 45th POTUS's efforts to subvert economic institutions started long before 2015 when he was a presidential candidate, and unexpectedly, he became the president-elect. As a presidential candidate, he questioned the validity of the monthly unemployment rate numbers reported by the Bureau of Labor Statistics (BLS). Before then, no presidential candidate questioned the credibility of BLS for its monthly reports of unemployment rates. During the same period, he attacked and chastised Janet Yellen-the Chairwoman of the Federal Reserve Bank (FRB)-for not raising the interest rate. These were deliberate signals to the electorate not to believe that the economy was on a recovery path and that these economic institutions (e.g. BLS and FRB) lacked credibility. In addition, these actions also revealed his intentions to subvert and reverse, but also to justify the need to exercise absolute authority over these economic institutions during his presidency.

As the president-elect in 2016, the incoming 45th POTUS quickly revealed how he would govern from the Oval Office. He attacked the president of Carrier Union in Indiana in a series of tweets such as:

"Chuck Jones, who is President of United Steelworkers 1999, has done a terrible job representing workers.

No wonder companies flee country!” (Donald J. Trump@realDonaldTrump (The tweets source is the same; therefore, it will not be repeated but each tweet cited will show the date), December 7, 2016).

"If United Steelworkers 1999 was any good, they would have kept those jobs in Indiana. Spend more time working-less time talking. Reduce dues." (December 7, 2016).

One can infer from these tweets that the 45th POTUS blamed the United Steelworkers Carrier Union for the outsourcing of jobs from Indiana; therefore, this could be construed as a strategic move to question the usefulness of membership in labor unions nationwide. Legal scholars cannot ascertain whether this was an early signal to the conservative Supreme Court Justices that if they ruled against the labor unions, this would delight the 45th POTUS and the conservative groups. The landmark Supreme Court ruling, which struck down the mandatory public sector union dues in June 2018, with respect to Janus v. American Federation of State, County and Municipal Employees (AFSCME), dealt a major blow to the few existing labor unions in the United States. The 45th POTUS celebrated this ruling in his tweet:

"Supreme Court rules in favor of non-union workers who are now, as an example, able to support a candidate of his or her choice without having those who control the Union deciding for them. Big loss for the coffers of the Democrats!" (June 27, 2018).

The 45th POTUS considered this Supreme Court ruling as a big win because this could eventually pave the way for the abolition of labor unions, similar to what Germany experienced in the 1930s, or the reversal to the yellow dog contract that existed prior to the Norris-La Guardia Act of 1932. The 45th POTUS continues to distort the markets by interfering in public and private enterprises such as the United States Postal Service, Amazon, Harley-Davidson Motorcycles, General Motors, and Wall Street. In addition, the 45th POTUS is relentless in challenging the Federal Reserve Bank (FRB), under his administration, for raising interest rates and now questions the independence of the FRB, which no previous president did (Some economists believed that the FRB boosted monetary growth in 1972 to help reelect President Nixon). Before the Fed finally capitulated, the 45th POTUS was displeased with Jerome Powellthe current Chairman of the FRB. In addition, the 45th POTUS considered the FRB to be "crazy," "out of control," and as his "biggest threat" for raising interest rates "too fast." In tweets and interviews, the 45th POTUS displayed blatant discontent with the FRB Chairman with the aim to undermine the independence of the most revered Central Bank in the world. In a tweet in July 2018, the 45th POTUS laid out the reasons for complaining about the Fed's tightening of monetary policy:

"The United States should not be penalized because we are doing so well. Tightening now hurts all that we have done. The U.S. should be allowed to recapture what was lost due to illegal currency manipulation and BAD Trade Deals. Debt coming due \& we are raising rates-Really?” (July 20, 2018).

From the excerpts of an interview with Trish Regan of Fox Business Network (FBN) in October 2018, the 45th POTUS lashed out at the Fed:

"The Fed is raising rates too fast and it's independent so I don't speak to them but I'm not happy with what he's doing because it's going too fast because you looked at the last inflation numbers they are very low."

"Can I be honest? I'm not blaming anybody. I put him there and maybe it's right, maybe it's wrong but I put him there." 
Interpretatively, these tweets and interviews signaled the 45th POTUS's implicit demand and preference for complete loyalty from Jerome Powell because he appointed ("I put him there") him as the Chair of the FRB.

In an interview with FBN on August 23, 2018, prior to the midterm elections, the 45th POTUS sent an implicit warning to economists, financial experts, and American voters that:

"If I ever got impeached, I think the market could crash, I think everybody would be very poor, because without this thinking (with finger pointed to the right side of his head (The author added this phrase based on video evidence in which the POTUS pointed to his head to show his brainpower and intelligence)), you would see-you would see numbers that you wouldn't believe in reverse."

These interviews and tweets capture his self-projections and self-deceptions as typified by his campaign slogan: "I alone can fix it," but more importantly, these tweets and interviews raise two crucial questions: What do economists or financial experts think of the 45th POTUS's discontent with the monetary policy stance of the FRB? Was the 45th POTUS sending an implicit warning to the stock market about his impeachment? From an objective viewpoint, one could deem this as the 45th POTUS's strategic groundwork to blame the FRB for any economic recession that may occur during his presidency. In addition, the 45th POTUS's impeachment warning was a signal to his millionaire and billionaire supporters, who invest in Wall Street, to sell their stocks if impeached. If his supporters in Wall Street followed the implicit instructions on what to do when impeached, this stock market tampering could lead to a massive stocks sell off or "stock market panic run" of an immense proportion with consequential global financial markets contagion. Essentially, the 45th POTUS signaled to investors that their trusts or mistrusts of the stock market depended solely on him, and that if impeached, they should let the stock market crash.

\subsection{Efforts to subvert and reverse political institutions}

The 45th POTUS started to sow mistrusts by peddling hate stories and false narratives across the political institutions during the 2016 presidential election as manifested by the unfounded accusation that a United States District Judge for the Southern District of California was judicially biased because of his Mexican heritage. During the 2016 presidential election, he also questioned the legitimacy of the election outcomes if he lost. The POTUS continues to sow mistrusts within the judicial system by questioning the independence of these agencies. This continues to manifest with the relentless vicious attacks on the Federal Bureau of Investigation (FBI), the Central Intelligence Agency (CIA), and the National Security Agency (NSA) in addition to the military and other law enforcement agencies.

Although the House and Senate Intelligence Committees as well as other investigatory bodies did not agree as to the level in which Russia and other countries interfered in the 2016 presidential elections, the occurrence has caused many voters to doubt the results of the elections. More importantly, this has eroded the trust in the political institutions of the United States. For instance, before the 2018-midterm elections, the Republicans in the House Intelligence Committee questioned the rationale for establishing the Special Counsel as well as the integrity of the FBI and the CIA rather than look into the Russian interference that occurred during the 2016 elections. The 45th POTUS continued to use tweets as the channel through which to condemn and to inform hardcore Republicans to distrust the activities of the FBI and CIA by dubbing them as the "criminal deep state." The sown distrusts are aptly captured in several tweets by the 45th POTUS:

"Look how things have turned around on the Criminal Deep State. They go after Phony Collusion with

Russia, made up Scam, and end up getting caught in a major SPY scandal the likes of which this country may never have seen before! What goes around comes around." (May 23, 2018).

The strength of the political institutions also lies in the fact that the voters can hold their representatives in both the House and the Senate accountable through the public sector whistleblowing protection laws (The Federal whistleblower legislation includes a statute protecting all government employees. In the federal civil service, the government is prohibited from taking, or threatening to take, any personnel action against an employee because the employee disclosed information that he or she reasonably believed showed a violation of law, gross mismanagement, and gross waste of funds, abuse of authority, or a substantial and specific danger to public safety or health. See http://legal-dictionary. thefreedictionary.com/Whistleblowing and Lee and Kleiner (2011) for detailed discussion of issues covered under the whistleblowing protection laws). Congress enacted the whistleblower law to help prevent corruption and to encourage people to expose misconduct, illegal, or dishonest activities for the good of society when these political representatives engage in corrupt activities while in office. Arguably, the newly introduced "nondisclosure agreement" into the White 
House by the 45th POTUS can be construed as a concerted effort to circumvent the rule of law as well as undermine the effectiveness of the whistleblowing protection laws in order to protect the 45th POTUS and many corrupt cronies in his administration (Legal experts and scholars consider these nondisclosure agreements as not enforceable, but the intention is to silence those employees in the White House who may have witnessed ongoing illegal activities and actions that undermine the rule of laws and weaken the political institutions).

Since his inauguration in January 2017, the 45th POTUS continues to use tweets to spread extreme fear and division, welcome government shutdown, and incite political chaos and violence as well as promote racial division and gender hatred:

"I don't care what the political ramifications are, our immigration laws and border security have been

a complete and total disaster for decades, and there is no way that the Democrats will allow it to be fixed without a Government Shutdown." (July 31, 2018).

"Border Security is National Security, and National Security is the long-term viability of our Country. A

Government Shutdown is a very small price to pay for a safe and Prosperous America!" (July 31, 2018).

The 45th POTUS preferred a government shutdown if Congress failed to fund the border wall. This was one of his strategies to cause unnecessary economic, political, and social chaos in his quest to undermine these institutions. This was an implicit incitation of political chaos and violence since the Republican Party no longer controlled the House of Representatives in the 116th Congress. Furthermore, in a recorded audio, during a closed-door meeting with Evangelical leaders on August 28, 2018, released or leaked to the media before the midterm elections of 2018, he told the Christian leaders that the midterm elections would not just be a referendum on him but also on their religion, and that:

"It's a referendum on free speech and the First Amendment, guaranteeing basic freedoms. It's not a question of like or dislike, it's a question that they will overturn everything that we've done and they will do it quickly and violently. And violently. There is violence. When you look at Antifa and you look at some of these peoplethese are violent people."

Based on an objective evaluation of these tweets, it is safe to conclude that the 45th POTUS was ready to use government shutdown to appease to the Republican base because he would adeptly shift the blame to the Democrats, which his hardcore base would believe. Since the Republicans no longer controlled the House of Representatives and he expected impeachment, promoting division through hate-creating stories and false narratives as depicted in these tweets and inciting political chaos and violence could be viewed as the 45th POTUS's channels to undermine the political institutions. Pundits and legal scholars who may underestimate the autocratic propensities need to consider the warning and ultimatum the 45th POTUS issued to the DOJ and the FBI when he spoke to a raucous, campaign-style rally in Indiana on August 30, 2018:

"All I can say is, Our Justice Department and our FBI, at the top of each because inside they have incredible people, but our Justice Department and our FBI have to start doing their job and doing it right and doing it now because people are angry. What's happening is a disgrace. And at some point, I wanted to stay out, but at some point if it doesn't straighten out properly, I want them to do their job, I will get involved and I'll get in there if I have to."

Obviously, this was a clear signal that the 45th POTUS demanded loyalty and his readiness to command the DOJ and FBI to do whatever he wants under the concept of law and order just as ruthless autocrats do worldwide.

It is important to emphasize that the survival of American democracy hinges on the strength of the judiciary system, especially with respect to how the law enforcement agencies go about enforcing the rule of law at different levels of government. The United States' judicial system continues to be under relentless attacks from the 45th POTUS and this has significantly undermined the judicial system with the complicit backing of Congressional Republicans, who held majorities in both the House and Senate before losing the House to Democrats in the 2018 midterm elections. When the Republicans controlled Congress, the House Judiciary Committee used their subpoena powers to obtain highly classified information from the DOJ and the FBI in strategically complicit coordinated efforts to subvert these relevant political institutions charged with enforcing the rule of law and protecting America's national security. They threatened these agencies with contempt of Congress if they failed to comply with these subpoenas. The complicity between the 45th POTUS and Congressional Republicans was captured in his tweet:

"So sad that the Department of 'Justice' and the FBI are slow walking, or even not giving, the redacteddocuments required by Congress. An embarrassment to our country!" (April 2, 2018). 
Before now, these highly classified documents were limited to Congressional leaderships dubbed as the "Gang of Eight," but was made available to Republican lawmakers and cleared staff, who readily and willingly obeyed the commands of the 45th POTUS.

Indisputably, the 45th POTUS has absolutely no confidence in the national intelligence agencies and this is, perhaps, one of the quickest ways to subvert and reverse the political institutions, destroy American representative democracy, and put its national security at risk. In a tweet, the 45th POTUS openly denigrated and ridiculed the national intelligence agencies for the whole world to see, which undoubtedly delighted the adversaries of the United States. This tweet questioned the integrity and the trustworthiness of the national intelligence agencies:

"The Intelligence people seem to be extremely passive and naive when it comes to the dangers of Iran. They are wrong! When I became President Iran was making trouble all over the Middle East, and beyond. Since ending the terrible Iran Nuclear Deal, they are MUCH different, but a source of potential danger and conflict. They are testing Rockets (last week) and more, and are coming very close to the edge. There economy is now crashing, which is the only thing holding them back. Be careful of Iran. Perhaps Intelligence should go back to school!" (January 30, 2019).

Intelligence gathering experts and pundits are astounded by the unprecedented 45th POTUS's motives to question the credibility of the national intelligence agencies in this era when the United States is experiencing cyber-attacks from its adversaries.

More importantly, the 45th POTUS's tweet was in stark contrast to the grim picture painted by the director of national intelligence, along with the directors of five other key intelligence agencies such as the CIA, FBI and NSA when they delivered their annual Worldwide Threat Assessment to Congressional lawmakers. They warned that the United States faces not only a "toxic mix" of threats, but also in danger of seeing its global influence wane as key adversaries, like Russia and China, position themselves to fill the resulting vacuum since the United States is abdicating its global leadership role around the world. Implicitly, the intelligence chiefs are warning about the 45th POTUS's underestimating and undermining the importance of prudent foreign policies.

\subsection{Efforts to subvert and reverse social institutions}

The 45th POTUS has taken numerous steps over the past four years to subvert the social institutions, especially the mainstream media-the ambit of free press and free speech. The efforts to subvert the mainstream media became profound and more noticeable in 2015 when he declared his candidacy for the 2016 presidential elections. During his campaign rallies in 2015 and 2016, he singled out many news reporters for public humiliation and vile verbal abuse. The 45th POTUS's rallies in 2017 and 2018 continued to replicate his campaign playbook of denigrating journalists, especially the entire free press, which is the foundation of a well-functioning democracy anywhere in the western world. In many rallies in 2018, the 45th POTUS told the audience not to trust or believe anything they see or read because the media, except FOX News, is fake news. This implicit signal to the public to ignore everything that comes from the mainstream media or any of the vital institutions continue to manifest in this era of COVID-19 pandemic.

The 45th POTUS's fixation with subverting the mainstream media, which is the core of the social institutions is aptly portrayed in the 25 "Mainstream Media Accountability Survey" questions (The 25 survey questions are not reproduced here in order to conserve on space. For these survey questions, see https://action.donaldjtrump.com/msnmedia-accountability-survey). A close examination reveals that several of the survey questions started with "Do you believe" and "Do you trust." These two key phrases stand out for what they convey because their use falls within the theories of self-deceptions and self-projections in that both reveal the personal intentions of the 45th POTUS to sow disbeliefs or division and political chaos/violence. Psychologists and philosophers consider self-deceptions and selfprojections as the processes by which one convincingly misleads oneself of the fact in order to conceal the knowledge of self-deceptions and/or self-projections. From the perspectives of psychologists, self-projection is a psychological defense mechanism in which individuals attribute characteristics they find unacceptable in themselves to another person. According to Mele (1998), self-deception is a process of rationalizing away the importance of any opposing evidence and logical argument; and as Mele (1998) pointed out, social factors, personal biases and/or intentions, fear, and cognitive repression influence the personal rationalization of this type of behavior.

Arguably, many tweets and interviews captured the 45th POTUS's self-projections and self-deceptions, but more importantly, these tweets and interviews promote division and hatred: 
"A very big part of the Anger we see today in our society is caused by the purposely false and inaccurate reporting of the Mainstream Media that I refer to as Fake News. It has gotten so bad and hateful that it is beyond description. Mainstream Media must clean up its act, FAST!" (October 25, 2018).

"Funny how lowly rated CNN, and others, can criticize me at will, even blaming me for the current spate of Bombs and ridiculously comparing this to September 11th and the Oklahoma City bombing, yet when I criticize them they go wild and scream, 'it's just not Presidential!"” (October 26, 2018).

Rather than tone down and/or take responsibility for his divisive and incendiary violent rhetoric, hate-creating stories, false narratives, and the demonization of his political opponents and the mainstream media, which he perfected over the past couple of years, he blamed the mainstream media. As a real estate developer in New York City and the host of "The Apprentice Show" on NBC for many seasons, the 45th POTUS believed and trusted the mainstream media, which he deceitfully used to promote his career for many decades.

During the 2016 presidential campaign, the 45th POTUS's political opponents from the Republican primary financially outraised him. However, he used his knowledge of the media environment to engage in strategic selfadvertising through unsolicited constant calls into many media outlets such as ABC, CBS, NBC, FOX News, CNN, and MSNBC to promote his candidacy for president. Then as a candidate, he trusted and believed in the mainstream media's objectivity, credibility, and transparency in news coverage because they provided free coverage of his candidacy (As a presidential candidate, the 45th POTUS engaged and received free self-advertising, which the advertising cost experts estimated to be roughly $\$ 6$ billion. See https://www.thestreet.com). As the POTUS, he wants the voters to disbelieve or mistrust, or to have no confidence in the mainstream media because they would not compromise their objectivity, credibility, and transparency in reporting the truth about the ongoing investigations of his administration.

Within the context of psycho-philosophical analysis of self-deceptions and self-projections and given that the 45th POTUS once worked or hosted in the mainstream media environment, it is safe to conclude that he believes and trusts that the mainstream media, even though not perfect, operates under the highest level of integrity in their news coverage. Similarly, the survey questions represent another attempt by the 45th POTUS to convince his base supporters to have negative perceptions of the objectivity and credibility of the news coverage from the mainstream media. An objective analysis based on these survey questions and the implied self-deceptions with respect to the mainstream media calls into question the integrity and the personal intentions of the POTUS.

Based on the theory of revealed preference, one can presume that these survey questions revealed the preferences of the 45th POTUS, which are congruent to those of the Republican Party, thus allowing scholars to provide objective evaluations and interpretations of his behavior without the specification of an explicit utility function. Furthermore, one can deduce from these survey questions that the 45th POTUS prefers a chaotic political environment where representative democracy is under suffocation and the EPS institutions are under severe attacks. He knows that the responses to these questions would support his implicitly revealed preferences. Whether research scholars agree or disagree, they cannot ignore the fact that the 45th POTUS intends to convince the Republican base to disbelieve or mistrust the mainstream media, thereby justifying his efforts to undermine the mainstream media before the 2020 presidential election and thereafter.

Similarly, scholars can also ask if the Democratic Party intends to undermine the EPS institutions. To address this issue and provide a balanced comparative analysis of both parties' intentions, the analysis of the survey questions from the Democratic Congressional Campaign Committee (DCCC) provided by their "Official Republican Leadership Survey" becomes paramount in order to see if their questions reveal their true intentions as well (The 11 survey questions of the DCCC are not reproduced here in order to conserve on space. For these and related survey questions, see https://action.dccc.org/survey/republican-leadership-survey). In comparing the survey questions from both parties, it is obvious that both survey questions are totally different. In examining the DCCC survey questions, three of the questions started with the phrase "What grade would you give." These questions are essentially about accountability and performance evaluation of leaderships at the Executive, the House, and the Senate held by the Republican Party before the Democrats regained the House in November of 2018. Furthermore, these questions could be construed as part of the DCCC's fundraising efforts to garner support for those Democratic candidates during the 2018 mid-term elections. The phrase, "mainstream media", never appeared in any of the 11 DCCC's survey questions. The logical conclusion is that the Democrats questioned the overall leaderships under the Republican Party: The 45th POTUS, the former Speaker of the House, and the Majority Leader in the Senate, but not the integrity of the mainstream media or any other EPS 
institutions; and that there was no intention to undermine the mainstream media.

Another attempt to discredit, sow discords, mistrusts and falsehoods is manifested by the open-ended social war between the 45th POTUS and the players of the National Football League (NFL) for kneeling down, during the playing of the national anthem, in protest against police brutality and racial injustice. For many American households, weekend football is the social event that promotes family gathering and unity; therefore, one can construe this is as an open instruction to all football fans to question the patriotism of the NFL players for protesting. This was the POTUS's signal to the public not to trust these NFL players because they are not patriotic enough. In addition to attacking NFL players as unpatriotic, the POTUS has also singled out individual players in the National Basketball Association for public humiliation. In addition, the 45th POTUS continues to attack both men and women from both parties as well minorities who criticize him by categorizing them as losers and people with low IQs. The POTUS's relentless efforts to foster mistrusts and falsehoods within the social institutions will undermine the foundation of social capital, social networks, and this would ultimately eviscerate the mainstream media, which is pivotal for the survival of social institutions and representative democracy in the United States.

\subsection{Theoretical summary}

Based on the historical records of presidential leaderships in the United States over the past two centuries, one can intuitively deduce that these presidents, though not perfect, embraced the dynamic American democratic ideologies with unquestionable commitments to promote trust, civility, and confidence (TCC) as well as national unity and security (NUS) through their policies (The $9 / 11$ and the assassination of terrorist leader-Osama-bin-laden are two illustrative examples. Before now, previous presidents exhibited the leadership traits that enabled voters to have trust and confidence in these institutions, even though these institutions are imperfect. Today, there is a high degree of mistrusts and lack of confidence in these institutions because the POTUS describes them as the "criminal deep state," which his supporters believe and some are willing to resort to violent acts. The Republicans in Congress have enabled the POTUS to accomplish his objectives of eroding trust in every institution by constantly deriding and denigrating the DOJ and the intelligence agencies). From the discussions about the efforts to subvert and reverse the EPS institutions, one can deduce that the 45th POTUS and the complicit Congressional Republicans provide the necessary pathways to achieve this goal. The 45th POTUS has strategically sown mistrusts and falsehoods (MTF) within the electorate so that they would have no confidence in the EPS institutions, especially the national intelligence agencies and the mainstream media. By now, it is obvious that the 45th POTUS is determined to overwhelm voters with endless hate-creating stories and false narratives with the goal to incite political chaos/chastise and violence $(P C V)$. With repeated hate-creating stories and false narratives, voters are now normalized to all forms of hatred and are indifferent in their consumption of truths and falsehoods. Eventually, $P C V$ is the 45th POTUS's weapon of intimidation as well as the strategic instrument with which to eliminate political opponents. Worldwide, presidents in autocratic countries use $P C V$ as the instrument of normalization and elimination of opponents because of its enormous chilling multiplier effects.

Furthermore, one cannot ignore the importance of external factors in terms of the United States' use of foreign policies $(F P)$ to build and solidify global alliances such as the United Nations (UN), North Atlantic Treaty Organization (NATO), World Trade Organization (WTO), and World Health Organization (WHO). These global alliances further contributed to strengthening the EPS institutions since the end of World War II. Arguably, all the previous presidential leaderships made significant contributions in strengthening these global alliances, which benefitted the EPS institutions and strengthened American democracy and its national security. The military and national intelligence agencies know the importance of prudent and strategic foreign policies in terms of our national security interests. In this era of nationalists' agenda espoused under the 45th POTUS, the global political economy is undergoing the wanton destruction of global alliances through corrupt and reckless transactional foreign policies $(F P)$. In the end, this would have adverse effects on the EPS institutions.

Methodizing and incorporating these assertions into equations (2) and (3) yield:

$$
I_{B}=R L_{B}\left(P L_{B}\right)^{\beta}\left(P L_{B} \cdot C B_{B}\right)^{\theta}\left(P L_{B} \cdot S M V_{B}\right)^{\mu}\left(P L_{B} \cdot T C C_{B}\right)^{\eta}\left(P L_{B} \cdot N U S_{B}\right)^{\alpha}\left(P L_{B} \cdot F P_{B}\right)^{\Omega}
$$

and

$$
I_{A}=R L_{A}\left(P L_{A}\right)^{-\delta}\left(P L_{A} \cdot C B_{A}\right)^{-\sigma}\left(P L_{A} \cdot V M V_{A}\right)^{-\psi}\left(P L_{A} \cdot M T F_{A}\right)^{-\lambda}\left(P L_{A} \cdot P C V_{A}\right)^{-\pi}\left(P L_{A} \cdot F P_{A}\right)^{-\phi}
$$


where $P L_{B} \cdot T C C_{B}, P L_{B} \cdot N U S_{B}$, and $P L_{B} \cdot F P_{B}$ represent the composite-interactive variables to capture the activities of all the previous presidential leaderships that built and strengthened the EPS institutions before 2017. In contrast, $P L_{A} \cdot M T F_{A}$, $P L_{A} \cdot P C V_{A}$, and $P L_{A} \cdot F P_{A}$ represent the composite-interactive variables that capture the activities of the 45 th POTUS to subvert and reverse the vital EPS institutions since 2017. Rewriting equations (14) and (15) in logarithm-linear forms yields:

$$
i_{B}=r l_{B}+\beta p l_{B}+\theta p l_{B} \cdot c b_{B}+\mu p l_{B} \cdot s m v_{B}+\eta p l_{B} \cdot t c c_{B}+\alpha p l_{B} \cdot n u s_{B}+\Omega p l_{B} \cdot f p_{B}
$$

and

$$
i_{A}=r l_{A}-\delta p l_{A}-\sigma p l_{A} \cdot c b_{A}-\Psi p l_{A} \cdot v m v_{A}-\lambda p l_{A} \cdot m t f_{A}-\pi p l_{A} \cdot p c v_{A}-\phi p l_{A} \cdot f p_{A}
$$

To comprehend the importance of the last three explanatory variables in equation (14) requires taking their partial derivatives, which yield:

$$
\begin{gathered}
\frac{\partial i_{B}}{\partial t c c_{B}}=\frac{\partial i_{B}}{\partial p l_{B}} \cdot \frac{\partial p l_{B}}{\partial t c c_{B}}=\eta \\
\frac{\partial i_{B}}{\partial n u s_{B}}=\frac{\partial i_{B}}{\partial p l_{B}} \cdot \frac{\partial p l_{B}}{\partial n u s_{B}}=\alpha
\end{gathered}
$$

and

$$
\frac{\partial i_{B}}{\partial f p_{B}}=\frac{\partial i_{B}}{\partial p l_{B}} \cdot \frac{\partial p l_{B}}{\partial f p_{B}}=\Omega
$$

Essentially, $\eta$ is the coefficient for trust, civility, and confidence; $\alpha$ is the coefficient for national unity and security; and $\Omega$ is the coefficient for rational foreign policies/alliances. Simply put, $\eta, \alpha$, and $\Omega$ are the additional built and strengthened EPS institutions coefficients that show the magnitude to which the previous transformational presidential leaderships, though not perfect, sowed and fostered trust, civility, and confidence; promoted national unity and security; and used rational foreign policies/alliances to enhance the effectiveness of the EPS institutions. In the past, several events at the national and international levels enhanced $T C C_{B}, N U S_{B}$, and $F P_{B}$, which contributed to building and strengthening the EPS institutions because these presidents showed the traits required of transformational leaders who are determined to promote $T C C_{B}, N U S_{B}$, and $F P_{B}$.

In contrast to the built and strengthened EPS institutions coefficients $(\eta, \alpha$, and $\Omega)$, the partial derivatives of equation (17) highlight the degree to which the 45th POTUS has undermined the EPS institutions. That is:

$$
\begin{gathered}
\frac{\partial i_{A}}{\partial m t f_{A}}=\frac{\partial i_{A}}{\partial p l_{A}} \cdot \frac{\partial p l_{A}}{\partial m t f_{A}}=-\lambda \\
\frac{\partial i_{A}}{\partial p c v_{A}}=\frac{\partial i_{A}}{\partial p l_{A}} \cdot \frac{\partial p l_{A}}{\partial p c v_{A}}=-\pi
\end{gathered}
$$

and

$$
\frac{\partial i_{A}}{\partial f p_{A}}=\frac{\partial i_{A}}{\partial p l_{A}} \cdot \frac{\partial p l_{A}}{\partial f p_{A}}=-\phi
$$


In other words, $-\lambda$ is the coefficient for mistrusts and falsehoods perpetrated through endless information distortions; $-\pi$ is the coefficient for intimidations or reprisals as well as political chaos and violence; and $-\phi$ is the coefficient for corrupt and destabilizing foreign policies. Above all, these coefficients $(-\lambda,-\pi$, and $-\phi)$ show the degree to which the 45th POTUS sows mistrusts and falsehoods, intimidates political opponents and incites political chaos and violence, and engages in corrupt foreign policies, which would have negative effects on the EPS institutions. The ongoing tariffs trade wars, the unresolved foreign interventions in presidential elections, and the complicity with autocratic leaders known for the assassinations of journalists and political opponents are good examples of reckless foreign policies that jeopardize America's national security.

The assassinations of journalists and political opponents in other countries will continue unchecked with chilling effects because the world can no longer depend on the United States to champion democratic norms. Coincidentally, United States' adversaries relish the 45th POTUS's dissolution of global alliances using corrupt and reckless $F P_{A}$, in contrast to past presidents' prudent $F P_{B}$. Given the 45th POTUS's open admirations of ruthless authoritarian leaders worldwide, the logical inference based on the intentions-revealing and self-deceptions statements is that the 45 th POTUS prefers to undermine the EPS institutions as depicted by equations (13) and (15). In general, these equations depict the behavior of autocrats in their desires to subvert and reverse the EPS institutional constraints once they attain power in democracies.

Above all, the built and strengthened EPS institutions coefficients $(\beta, \theta, \mu, \eta, \alpha$, and $\Omega)$ show the extent to which previous presidential leaderships with democratic ideals in conjunctions with the legislative and the judiciary branches solidified the rule of law and the EPS institutions. In other words, they provided the reinforcements, which built and strengthened the EPS institutional foundations of representative democracy in the United States. In contrast, the entire subvert and reverse EPS institutions coefficients $(-\delta,-\sigma,-\psi,-\lambda,-\pi$, and $-\phi)$ show the degree to which the 45 th POTUS along with the complicit Republicans in different branches of government and the unwavering support from the vocal minority voters chipped away at the rule of law by not holding 45th POTUS accountable despite many revealed violations.

In the end, what do research scholars expect the future of the EPS institutions to be in the United States if the 45th POTUS had won reelection for a second-term in office? Combining equations (16) and (17) provides the theoretical prediction and the assessment of the expected future strength of the EPS institutions in the United States. That is:

$$
\begin{aligned}
& i_{F}=r l_{F}+(\beta-\delta) p l_{F}+(\theta-\sigma) p l_{F} \cdot c b_{F}+\left(\mu p l_{F} \cdot s m v_{F}-\psi p l_{F} \cdot v m v_{F}\right)+ \\
& \left(\eta p l_{F} \cdot t c c_{F}-\lambda p l_{F} \cdot m t f_{F}\right)+\left(\alpha p l_{F} \cdot n u s_{F}-\pi p l_{F} \cdot p c v_{F}\right)+(\Omega-\phi) p l_{F} \cdot f p_{F}
\end{aligned}
$$

where $r l_{F}=r l_{B}+r l_{A}$ and the subscript $F$ stands for future with respect to all the variables defined earlier. The $r l_{F}$ hinges on the damage to the rule of law since 2017, especially in this era of significant legislative reversals. In other words, the United States would have experienced significant and perhaps irreparable subversal and reversal in the strength of its EPS institutions if the 45th POTUS had won a second-term because he would have substantially subverted and reversed the legislative achievements of the previous presidents. Since the will and support of the silent majority voters superseded those of the vocal or diehard minority voters who supported the 45th despite his open autocratic impulses, $\mu p l_{F} \cdot s m v_{F}>\psi p l_{F} \cdot v m v_{F}$ eventually prevented the outcome that would have yielded $\beta-\delta=\theta-\sigma=\eta-\lambda=\alpha-\pi=\Omega$ $-\phi \leq 0$ if the 45th POTUS had won a second-term in office. What is difficult to predict is how long it would take to turnaround the subverted of the rule and the reversed EPS institutions to their pre-2017 levels.

In summary, Figure 2 provides the visual analysis of the rule of law and the strength of the EPS institutions in different periods of presidential leaderships as explained by equations (2)-(24). Before 2017 when there were no subversal and reversal in the rule of law, $\frac{\partial i_{B}}{\partial r l_{B}}=1$ ceteris paribus; and $i_{B}$ sloped upward due to all the exogenous factors (see equations (14) and (16)) that built and strengthened the EPS institutions. The turning points $M$ and $N$, which occurred in 2017, marked the beginning of the subversal and reversal process when $\frac{\partial i_{A}}{\partial r l_{A}}=\frac{\partial i_{F}}{\partial r l_{F}}<1$; and $i_{B}$ transformed into $i_{A}$, which turned downward sloping due to the entire negative exogenous factors when the Republican-controlled and/or divided Congress could not exert the constitutionally required checks and balances on the 45th POTUS's abuses of executive power (see equations (15) and (17)). 


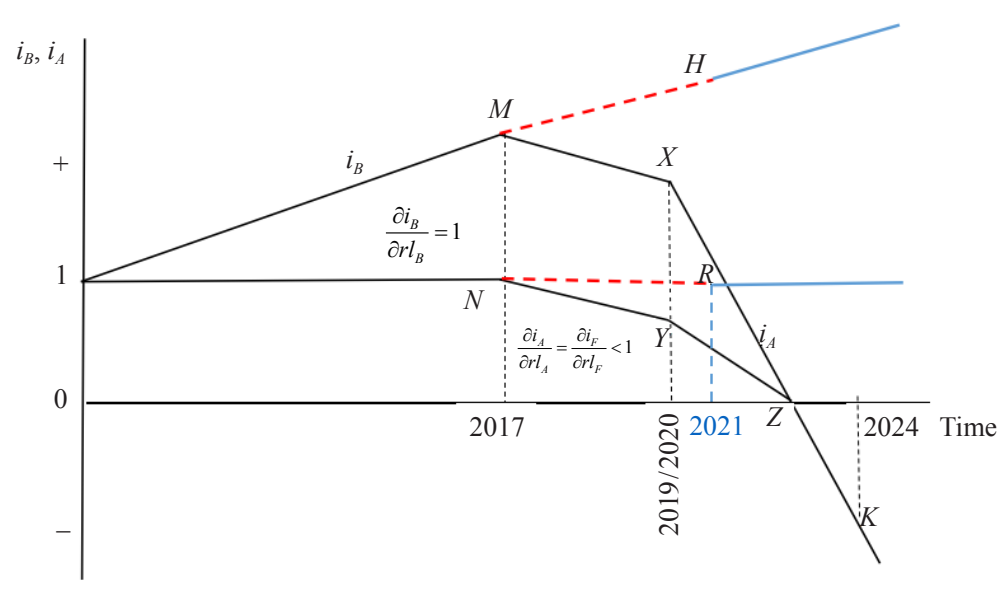

Figure 2. The Strength of EPS Institutions in the United States, Before and After 2017

Next, the turning points $X$ and $Y$ occurred in 2019 and 2020. In early 2019, the newly appointed Attorney General (AG) testified during his Congressional confirmation hearing that the 45th POTUS could exercise unchecked executive powers. The impeachment in late 2019 and the trial in early 2020 marked the most significant milestone in the subversal of the rule of law and the reversal of the EPS institutions, which may converge in the negative zone before 2024 if the impeached 45th POTUS retains power.

Many legal experts and political pundits interpreted the AG's testimony to mean that the 45th POTUS could not be constrained by Congressional oversights and could therefore subvert the rule of law and reverse the EPS institutions. In addition, since there was not a single witness during the impeachment trial, which resulted in acquittal of the 45th POTUS in the Senate in 2020, experts interpreted the outcome as the 45th POTUS being above the rule of law. More importantly, political pundits interpret this outcome as indicative of the rapid erosion in the rule of law, that is, $\frac{\partial i_{A}}{\partial r l_{A}}=\frac{\partial i_{F}}{\partial r l_{F}}<1$; thus the rapid downward sloping $i_{A}$ because of the broken constitutional rule of law. Given the fast moving pace to subvert the rule of law and reverse the EPS institutions, both of which would eventually converge to zero benchmark when the subversal process is complete or to negative benchmark when the reversal process is complete. Both may occur between now and 2024 if the 45th POTUS wins the presidential reelections. It is difficult to measure the rapidity at which $\frac{\partial i_{A}}{\partial r l_{A}}=\frac{\partial i_{F}}{\partial r l_{F}}<1$ and $i_{A}$ fall in Figure 2. The extent to which the 45th POTUS and the Republican Party chipped away at the rule of law, democratic principles, and further undermine the EPS institutions depended on which Party controls the White House and Congress in 2021 and beyond as well as the unchecked 45th POTUS's autocratic aspirations.

If the 45th POTUS had won the 2020 presidential elections, Congressional Republicans would have enabled him to use of law and order politics to achieve his objective of complete subversal of the rule of law and the reversal of the ESP institutions, thus the advent of tyrannical autocracy. This would have unraveled or led to the ultimate death of democracy in the United States as allude to by Smith (2018), Levitsky and Ziblatt (2018), Greenberg (2020), and Acemoglu (2020). In other words, the United States would have found itself at point $K$ in Figure 2 by 2024 and perhaps into the foreseeable future. Line segments $N Y Z$ and $M X Z$ represent the subversal of the rule of law and the EPS institutions, respectively, while line segment $Z K$ captures the reversal of both if the 45th POTUS's use of law and order prevail. Overall, line segments $N Y Z K$ and $M X Z K$ represent the unraveling and collapse of democratic norms. With the Democrats winning back the White House and the House of Representative, this means that by 2021, one could expect the restorations of the fractured rule of law and the EPS institutions depicted by the red dashed lines $N R$ and $M H$, respectively. In essence, restoring the rule of law, rebuilding the EPS institutions, and the return to normalcy with respect to democratic norms could begin in 2021.

If the will and support of the unwavering vocal minority voters who supported the 45th POTUS's open autocratic aspirations had superseded those of the courageous silent majority voters, $\mu p l_{F} \cdot s m v_{F}<\psi p l_{F} \cdot v m v_{F}$ would have yielded a disastrous outcome for the rule of law and the EPS institutions $(\beta-\delta=\theta-\sigma=\eta-\lambda=\alpha-\pi=\Omega-\phi \leq 0)$, and the following critical events would have occurred during the second-term of the 45 th POTUS because the complicit 
Republican Party would have enabled him to achieve authoritarian power, which they crave:

1. The 45th POTUS would have bullied or fired the Chairman of the Federal Reserve Bank such that the FRB would no longer be an independent economic institution, which would have given the 45th POTUS an unprecedented control of monetary policy. The 45th POTUS would have ordered the Bureau of Labor Statistics not to report the monthly unemployment rates if the economy is in a recession because the unemployment rate would reflect negatively on his administration (Recently, the FRB decreased interest rate based on the premise that the tariffs trade wars was affecting the economy. Given that the unemployment rate is roughly 3.6 percent, which is below the natural rate of unemployment, many economists and political pundits believe that the 45th POTUS's relentless intimidation of the FRB's Chairman was instrumental in the FRB's lowering of interest rate).

2. The 45th POTUS and the complicit Congressional Republicans would continue to pack the Supreme Court and Federal Courts with conservative justices and federal judges, respectively. The Attorney General (AG) of the United States would unofficially become the personal lawyer of the 45th POTUS and this would further enable the 45th POTUS to subvert the rule of law and reverse the EPS institutions by overturning previously established laws such as Roe $\mathrm{v}$ Wade and/or the Affordable Care Act in order to pacify the 45th POTUS and the hardcore Republican base.

3. The 45th POTUS would have ordered the AG to arrest and investigate/prosecute political opponents or protesters and his base supporters would have been further emboldened to engage in relentless harassments and endless intimidations of political opponents. Similarly, the POTUS would have ordered the arrests, detentions, and prosecutions of journalists and subject them to libel lawsuits nationwide or journalists disappearing because his hardcore base supporters would have engaged in political retaliations.

4. The 45th POTUS would have been more emboldened to continue with his unprecedented disregard of Congressional legislative oversights, which the Republicans in Congress enabled and he would have achieved the complete politicizations of the DOJ, the State Department, the Supreme Court, and all military establishments.

5. The 45th POTUS would have ordered the revocation of the licenses of news outlets such as ABC, CBS, NBC, MSNBC, and CNN if they continued to report about the corruption of his administration.

6 . The 45th POTUS would have ordered the military and the police to arrest and detain any group or individual that protests against his administration on political issues.

Many Americans who are already normalized to the 45th POTUS's racially and politically divisive rhetoric as well as the inhumane detentions and deportations of immigrants would be indifferent if these critical events occurred because the United States is going through the era of extreme racial-gender divisions, hyperpartisan political animosity, and the normalization of the executive abuses of power. Simply put, half of the electorate already believed the other co-equal branches of government cannot hold the 45th POTUS accountable for any visible wrongdoings as long as he occupied the White House.

Research scholars and political pundits are hesitant to ask pertinent questions for empirical analysis. If the 45th POTUS won the reelection in 2020, would the Republican Party have proposed and supported legislation to abolish the two-term limits? Would the Republican Party have supported a POTUS-for-life in order for them to maintain power indefinitely? How would the Republican Party have reacted if their candidate won the popular votes but lost the Electoral College votes in 2020 or in any foreseeable future elections? Given all the indications that the EPS institutions and the Constitution of the United States are under stress and survival tests, scholars and voters cannot continue to ignore these tough questions. The efforts to gerrymander congressional districts, the relentless voter suppressions strategies nationwide, and the apparent openness to foreign interferences in elections may continue to favor the Republican Party, and this may continue into the near future.

The political reality is that the control of the White House and a divided Congress may continue, and this may still empower the 45th POTUS to subvert the constitutional rule of law and reverse the EPS institutions in order to achieve his autocratic aspirations. Furthermore, given the Republican Party's continued obsequiousness and complicity with the 45th POTUS in the current hyperpartisan political environment, one should not have been surprised to see the Republican Party supporting the legislation to abolish the two-term limits and embrace the idea of a lifetime POTUS as long as this would enhance their chances to control the three co-equal branches of government. The concept of a president for life is gaining momentum and support in western democracies; and there is every indication that the 45th POTUS and the Republican Party may embrace the idea of changing the Constitution, under the disguise of law and order to control and weaponize all the branches of government. One should expect complete outrage and political 
violence from the Republican Party if their presidential candidate wins the popular votes but loses the Electoral College votes in 2020 or future elections.

Every American is well aware that the 45th POTUS openly revealed his adoration for ruthless autocratic leaders in other countries where there are no institutional constraints. Simply put, the 45th POTUS adored autocratic leaders in countries where ruthless authoritarian leaders are above the rule of law; therefore, he would prefer the same experience for the United States. According to Liptak (2018) and Stewart (2018), the 45th POTUS praised the Chinese president's power grab during the closed-door remarks to his Republican donors at his Mar-a-Lago estate on March 3, 2018, and he expressed that this would be fine in the United States:

"He's now president for life. President for life. No, he's great. And look, he was able to do that. I think it's great. Maybe we'll have to give that a shot someday."

The 45th POTUS also expressed his "great respect" for President Xi and "very good relationship" with him during a meeting with US governors in March 2018.

Skeptics who are not convinced by the theoretical analysis that the 45th POTUS posed a big threat to the rule of law and the EPS institutions need to revisit global political history to learn that many countries that once had strong economies and EPS institutions collapsed under autocratic leaderships. Given the degree of obsequiousness and complicity by the Republican Party and had it not been for the will and bravery of the silent majority voters, the United States would have joined the group of autocratic countries in the 21st century. Put differently, when the 45th POTUS subverts the rule of law, reverses the EPS institutions, and other traditional norms, only the rational and courageous majority voters can come to the rescue of the rule of law, the EPS institutions, and representative democracy in the United States.

\section{Concluding remarks and political implications}

The study provides an analytical framework that permits a new perspective of the relationship between presidential leaderships and EPS institutions in the United States, and argues that representative democracy could transition into autocracy if the 45th POTUS undermines the rule of law and subverts and reverses the strong EPS institutions that check his executive power overreach. Before 2017, every POTUS demonstrated democratic propensities and avoided activities that eroded public trust and confidence in the EPS institutions, thus they contributed to strengthening the rule of law that reinforced the guardrails, which allowed the EPS institutions to function as designed for representative democracy. This was possible because the strong bipartisan Congress did not abdicate its oversight responsibilities until 2017.

With Republicans in control of the White House and a divided Congress, which may continue into the foreseeable future given the nationwide gerrymandered congressional districts and voter suppressions, one should not expect an immediate end to the obsequiousness because the 45th POTUS will continue to engage in subverting and reversing the rule of law and the vital EPS institutions. As long as the United States is locked in this hyperpartisan politically polarized environment, voters would continue to see themselves from different lenses of ideological political prisms in which half of the country would value party allegiance over the allegiance to the Constitution. Under this scenario, a POTUS with autocratic propensities will continue to exploit the division to subvert and reverse the rule of law and the EPS institutions in order to achieve his autocratic impulses, congruent to those of the Republican Party. Arguably, roughly half of the United States will be satisfied if the 45th POTUS succeeded in transitioning into autocracy. With constant barrage of hate-creating stories and false narratives, the upsurge in political chaos and violence would overwhelm the remaining half of the country, and this would ultimately eviscerate the rule of law and the strong EPS institutions.

Levitsky and Ziblatt (2018) recently asserted that "institutions alone are not enough to rein in elected autocrats," and this further corroborates Sachs's (2003a-b) assertions that "institutions matter, but not for everything" and that "institutions don't rule." This paper also corroborates the validity of these assertions with logical theoretical analysis and verifiable documentary communicative evidence to show that presidential leaderships matter with respect to strong or weak EPS institutions. The United States is the most respected country for its representative democracy, which is now unraveling for the world to see according to Greenberg (2020) and Acemoglu (2020). In this era of global chaos and socio-political violence, it provides a new perspective or case study with enough documentary evidence with 
which to analyze the autocratic propensities revealed by the 45th POTUS. Political and international legal experts agree that the world is experiencing globally contagious autocratic presidential leaderships; therefore, research scholars need to reevaluate the relationship between presidential leaderships and the vital EPS institutional pillars of American democracy because one can no longer take for granted the independence and strength of the EPS institutions in advanced countries, such as the United States.

Since many economists concur that institutions and/or leaders matter in growth, this paper further contributes to the theoretical debate by using the 45th POTUS-EPS institutions nexus as an illustrative example to show that presidential leaderships matter since they wield enormous power and influence over the EPS institutions once they attain political power. Research scholars who assert and conclude that institutions and/or leaders matter in either positive or negative economic growth also need to consider the core argument illustrated by these equations, which show that presidential leaderships matter in determining the survivability of the EPS institutions in the United States and elsewhere, even though it is difficult to quantify with data. Whether or not one uses data for econometric or statistical analysis, what political pundits and institutional theorists cannot predict is the degree of damage to the EPS institutions. Furthermore, for the United States, it is reasonable to conclude that if the 45th POTUS had won a second term in office, the Republican Party would have continued and intensified their obsequiousness, and in the end, the damage to these vital institutions would have been irreparable.

As for economic growth implications, research scholars need to reexamine their debatable perspective with respect to the primacy of institutions in economic growth and development because their empirical results based on proxy or instrumental variables are at best ambiguous, if not controversial, especially since strong EPS institutions are no longer sacrosanct in the United States and in other advanced democracies. This is important because presidential leaders and leaderships at the other co-equal branches of government with democratic principles that research scholars normally associated with western democracies are gradually revealing and embracing autocratic philosophies. In terms of political implications, the global economy is in an era of apparent transition from democracies to autocracies as manifested by the remarkable changes in the political ideologies of presidential leaderships, the undermining of legislative oversight powers, and trusts replaced with mistrusts. This means that in this era of globalization, scholars should not expect significant differences between democracies and autocracies as elected would-be autocrats in strong democracies such as the United States can easily turn trusts, civility, and confidence $\left(T C C_{B}\right)$ into mistrusts and falsehoods $\left(M T F_{A}\right)$. In addition, the events that once promoted national unity and security $\left(N U S_{B}\right)$ have turned into political theatre to intimidate and promote chaos and violence $\left(P C V_{A}\right)$. The prudent foreign policies $\left(F P_{B}\right)$ that solidified global alliances have turned into transactional quid pro quo foreign policies $\left(F P_{A}\right)$ in order to subvert the rule of law and reverse the strong EPS institutions. This would ultimately subvert and reverse the global alliances that the United States used to shape and lead the world since World War II.

Given the 45th POTUS's revealed preference for autocracy and his admirations for autocratic leaders worldwide and based on his revealed plan to withdraw the United States from some important global alliances, it is conceivable that he would have subverted and reversed these global alliances. The 45th POTUS relished the concept of subversal and reversal as manifested by NAFTA, the 26 years old trade agreement between the United States, Canada, and Mexico, which the 45th POTUS turned to USMCA; therefore, pundits should not underestimate the subversal and reversal of global alliances, especially the 71 years old North Atlantic Treaty Organization (NATO). The 45th POTUS would have cherished turning NATO to the Orderly Treaty of Autocratic Nations (OTAN), United Nations (UN) to Nations Unwanted (NU), World Trade Organization (WTO) to Organization of Trade Warriors (OTW), and World Health Organization (WHO) to Organization of Health Warriors (OHW) for the 21st century. Pundits and foreign policy experts, who may underestimate the global autocracy wave, may soon realize that the global autocracy contagion is apparently at the take-off stage in the United States, and this could reach the age of worldwide revealed preference for nationalism and autocracy.

Finally, the 45th POTUS would have succeeded in accomplishing his objective of complete subversal of the rule of law and the reversal of the EPS institutions if he had won the 2020 reelection. Essentially, this would have eviscerated all democratic norms, but more importantly, this would have overwhelmed the ordinary rational silent majority voters who would have been intimidated to join the camp of the vocal minority voters who are already normalized by the 45th POTUS's self-projections and self-deceptive statements. Eventually, Americans would have succumbed to the strategic self-projections and self-deceptions statements or tweets of the 45th POTUS. Ultimately, this would have resulted 
in complete subversal of the rule of law and the reversal of the strong EPS institutions; and in the end, American democracy would have transformed to a law and order autocratic-democracy where people vote in sham. Overall, this paper provides the algebraic and graphical illustrations of the 45th POTUS's subversal of the rule of law and the reversal of the EPS institutions and thus the unraveling of American democracy, which Smith (2018), Greenberg (2020), and Acemoglu (2020) alluded to in their studies. Based on the outcome of the 2020 presidential election, one can conclude that only the rational and courageous silent majority voters, not the rule of law and/or the EPS institutions, can curtail or rein in the 45th POTUS's or any POTUS's autocratic aspirations.

\section{Acknowledgements}

The author is grateful to the editor, the three anonymous referees, and Steve Skinner for their insightful comments on the earlier draft of this paper. The author acknowledges the funding from the 2020-2021 CSU-AAUP Research Grant. The views expressed in this paper are those of the author. The author is responsible for the remaining errors in the paper.

\section{References}

Acemoglu, D. (2020). America's democratic unraveling: Countries fail the same way businesses do, gradually and then suddenly. Foreign Affairs. Published by the Council of Foreign Relations. https://www.foreignaffairs.com/articles/ united-states/2020-06-15/americas-democratic-unraveling.

Acemoglu, D. (2009, November 18). What makes a nation rich? one economist's big answer. Esquire. http://www. esquire.com/features/best-and-brightest-2009/world-poverty-map-1209?page=all.

Acemoglu, D. (2003). Root causes: A historical approach to assessing the role of institutions in economic development. Finance and Development, 27-30.

Acemoglu, D., \& Robinson, J. A. (2008). The Role of Institutions in Growth and Development. The International Bank for Reconstruction and Development/The World Bank On behalf of the Commission on Growth and Development. Working Paper No. 10.

Acemoglu, D., \& Robinson, J. A. (2006). De facto political power and institutional persistence. American Economic Review, 96(2), 325-330.

Acemoglu, D., Johnson, S., Robinson, J. A., \& Yared, P. (2005). From education to democracy? American Economic Review, 95, 44-49.

Acemoglu, D., Johnson, S., \& Robinson, J. A. (2002). Reversal of fortune: Geography and development in the making of the modern world income distribution. Quarterly Journal of Economics, 117(4), 1231-1294.

Acemoglu, D., Johnson, S., \& Robinson, J. A. (2002). An African Success Story: Botswana. Centre for Economic Policy Research.

Acemoglu, D., Johnson, S., \& Robinson, J. A. (2001). The colonial origins of comparative fevelopment: An empirical investigation. American Economic Review, 91(5), 1369-1401.

Alberta, T. (2019). American Carnage: On the Front Lines of the Republican Civil War and the Rise of President Trump. New York, NY: Harper Collins Publishers.

Barro, R. J. (1997). Determinants of Economic Growth: A Cross-Country Empirical Study. Cambridge, Massachusetts: The Massachusetts Institute of Technology Press.

Barro, R. J., \& Xavier Sala-i-Martin (2004). Economic Growth. Cambridge, Massachusetts: The Massachusetts Institute of Technology Press.

Barro, R. J. (1999). Determinants of democracy. Journal of Political Economy, 107, 158-183.

Barro, R. J. (1997). Determinants of Economic Growth. Cambridge, Massachusetts: The Massachusetts Institute of Technology Press.

Barro, R. J. (1991). Economic Growth in a Cross-Section of Countries. Quarterly Journal of Economics, 106, 407-443.

Besley, T., \& Kudamatsu, M. (2007). Making Autocracy Work. The Suntory and Toyota International Centres for Economics and Related Disciplines: London School of Economics and Political Science, DEDPS 48.

Buchanan, J., \& Tullock, G. (1962). The Calculus of Consent: Logical Foundations of Constitutional Democracy. Ann Arbor, Michigan: University of Michigan Press. 
Bueno de Mesquita, B., Smith, A., Siverson, R. M., \& Marrow, J. D. (2003). The Logic of Political Survival. Cambridge, Massachusetts: The Massachusetts Institute of Technology Press.

Bueno de Mesquita, B., Marrow, J. D., Siverson, R. M., \& Smith, A. (2002). Political institutions, policy choice and the survival of leaders. British Journal of Political Science, 32(4), 559-590.

Chabal, P., \& Daloz, J. P. (1999). Africa Works: The Political Instrumentalization of Disorder. Bloomington, Indiana: The International African Institute and Indiana University Press.

Dorf, M. C. (2016). Trump's law and order versus the rule of law. Verdict: Legal Analysis and Commentary From Justia. https:/verdict.justia.com/2016/07/27/trumps-law-order-versus-rule-law.

Easterly, W., \& Levine, R. (2003). Tropics, germs, and crops: How endowments influence economic development. Journal of Monetary Economics, 50(1), 3-39.

Glaeser, E. L., Porta, R. L., Lopez-de-Silanes, F., \& Shleifer, A. (2004). Do institutions cause growth. Journal of Economic Growth, 9(3), 271-303.

Greenberg, K. J. (2020, February 28). American democracy is unraveling before our eyes. The Nation. https://www. thenation.com/article/politics/democracy-erosion-trump/.

Gur, R. C., \& Sackeim, H. A. (1979). Self-deception: A concept in search of a phenomenon. Journal of Personality and Social Psychology, 37(2), 147-169.

Hall, R. E., \& Jones, C. (1999). Why do some countries produce so much more output per worker than others. Quarterly Journal of Economics, 114, 83-116.

Jones, B. F., \& Olken, B. A. (2005). Do leaders matter? national leadership and growth since World War II. Quarterly Journal of Economics, 835-864.

Kaufman, D., \& Kraay, A. (2002). Growth Without Governance. The World Bank policy research working paper series 22928, Washington, D.C.

Knack, S., \& Keefer, P. (1995). Institutions and economic performance: Cross-country tests using alternative measures. Economics and Politics, 7, 207-227.

Knutsen, C. H. (2010). Africa's Growth Tragedy Revisited: Weak States and Strong Rulers. Centre for the Study of Civil War, PRIO, University of Oslo, Norway.

Lee, K., \& Kleiner, B. (2011). Whistleblower retaliation in the public sector. Public Personnel Management, 40(4): 341 348.

Levitsky, S., \& Ziblatt, D. (2018). How Democracies Die. New York: Crown-Penguin Random House, LLC.

Levitsky, S., \& Ziblatt, D. (2016b, December 16). Is Donald Trump a threat to democracy? The New York Times. https:// www.nytimes.com/2016/12/16/opinion/sunday/is-donald-trump-a-threat-to-democracy.html.

Levitsky, S., \& Ziblatt, D. (2016a, November 7). Democracy's fate may hang in the balance even if Donald Trump loses. Vox. https://www.vox.com/polyarchy/2016/11/7/13547642/democracy-fate-trump-loss6.

Liptak, K. (2018, March 3). Trump on China's Xi consolidating power: 'Maybe we'll give that a shot some day.' https:// www.cnn.com/2018/03/03/politics/trump-maralago-remarks/index.html.

Mele, A. R. (1998). Two paradoxes of self-deception. Self-Deception and Paradoxes of Rationality. CSLI Publications.

North, D. (1971). Institutional change and economic growth. The Journal of Economic History, 31, 118-125.

North, D. C., \& Thomas, R. P. (1973). The Rise of the Western World: A New Economic History. Cambridge, Massachusetts: Cambridge University Press.

North, D. (1990). Institutions, Institutional Change, and Economic Performance. New York: Cambridge University Press.

Olson, M. (2003). Dictatorship, democracy and development. Democracy, Governance and Growth. Ann Harbor, Michigan: The University of Michigan Press.

Persson, T., Roland, G., \& Tabellini, G. (1997). Separation of powers and political accountability. Quarterly Journal of Economics, 112, 1163-1202.

Persson, T., \& Tabellini, G. (2006). Democracy and development: The devil in the details. American Economic Review, 96(2), 319-324.

Przeworski, A., Alvarez, M. E., Chiebub, J. A., \& Limongi, F. (2000). Democracy and Development: Political Institutions and Well-Being in the World, 1950-1990. Cambridge: Cambridge University Press.

Rodrik, D. (2008). A practical approach to formulating growth strategies. The Washington Consensus Reconsidered: Towards New Global Governance. DOI:10.1093/acprof:oso/9780199534081.003.0016.

Rodrik, D., \& Wacziarg, R. (2005). Do democratic transitions produce bad economic outcomes? American Economic Review, 95, 50-55.

Rodrik, D., Subramanian, A., \& Trebbi, F. (2002). Institutions Rule: The Primacy of Institution Over Geography and 
Integration in Economic Development. National bureau of economic research working paper No. 9305.

Rodrik, D. (2002). Institutions, Integration, and Geography: In Search of the Deep Determinants of Economic Growth. In Search of Prosperity: Analytic Country Studies on Growth. https://www.ias.edu/sites/default/files/sss/pdfs/ Rodrik/Research/institutions-integration-geography.pdf

Sachs, J. D. (2003a). Institutions Don't Rule: Direct Effects of Geography on Per Capita Income. National bureau of economic research working paper No. 9490.

Sachs, J. D. (2003b). Institutions matter, but not for everything: The role of geography and resource endowments in development shouldn't be underestimated. Finance and Development, 38-41.

Samuelson, P. A. (1938). A note on the pure theory of consumers' behaviour. Economica, New Series, 5(17), 61-71.

Samuelson, P. A. (1948). Consumption theory in terms of revealed preference. Economica, New Series, 15(60), 243-253.

Smith, E. E. (2018). 'Law and Order' politics often undermines the rule of law. Vox. https://www.vox.com/mischiefs-offaction/2018/7/9/17550116/trump-tweet-law-and-order.

Stewart, E. (2018). Trump says China's Xi is 'President for Life'-and maybe America should try it. Vox. https://www. vox.com/policy-and-politics/2018/3/4/17077642/trump-xi-china-fundraiser. 